\title{
Nicotine Dependence and Periodontal Status among Tobacco Users in a Dental Hospital of Kathmandu Valley
}

\author{
Dr. Sirjana Dahal, ${ }^{1}$ Dr. Prakash Poudel, ${ }^{2}$ Dr. Shradha Adhikari ${ }^{1}$ \\ ${ }^{1}$ Department of Community and Public Health Dentistry, Kathmandu Medical College and Teaching Hospital, Kathmandu, Nepal; \\ ${ }^{2}$ Department of Orthodontics and Dentofacial Orthopaedics, Kathmandu Medical College and Teaching Hospital, Kathmandu, Nepal.
}

\begin{abstract}
Introduction: Tobacco use in any form (smoking or smokeless) has been recognised to be a significant risk factor for the development and progression of periodontal disease.

Objective: To assess the nicotine dependence and periodontal status among tobacco users of a dental hospital of Kathmandu Valley and determine their association.

Methods: A cross-sectional study was conducted among 164 tobacco users visiting a dental hospital of Kathmandu. Nicotine dependence was assessed using the Fagerstrom Test for Nicotine Dependence-Smokeless Tobacco and the Fagerstrom Test for Nicotine Dependence. Their periodontal status was examined using community periodontal index and loss of attachment. Data were entered in Microsoft excel sheet and analysed in IBM SPSS Statistics for Windows, version 20. Mean, standard deviation, proportion, and percentage were calculated depending upon the nature of data. Chi-square test and Fisher's exact test were used to determine the association between different variables.

Results: Most of the tobacco smokers (34,63.0\%), chewers (12, 48.0\%), and dual users (smoke=55, 64.7\%; smokeless= 46, 54.1\%) in this study showed low nicotine dependence. Majority of the tobacco users surveyed had periodontal pocket of 4-5 mm (73, 44.5\%) and loss of attachment of 6-8 mm (79, 48.2\%). Tobacco smokers and chewers having moderate or high nicotine dependence had periodontitis significantly higher than those who had low dependence.

Conclusion: The findings in this study conclude that most of the individuals using tobacco in any form have periodontal diseases. Nicotine dependence is significantly associated with increased periodontal breakdown.

Keywords: Loss of attachment; nicotine dependence; periodontal pocket; tobacco.
\end{abstract}

\section{INTRODUCTION}

Tobacco products are made from fresh leaves of plants in genus "Nicotina" of Solanaceae family and are consumed in smoked, chewed, or snuffed form. ${ }^{1}$ Use of tobacco has a large impact on systemic and oral health of an individual. ${ }^{2}$ Tobacco contains more than 3800 chemicals including carbon monoxide, nicotine, hydrogen cyanide, and reactive oxidising radicals among which 60 are carcinogenic. ${ }^{3}$

Nicotine is an active content of tobacco causing physical and psychological dependence. ${ }^{4}$ In Nepal, $28.9 \%$ of adults of 1569 years (48.3\% of men, $11.6 \%$ of women) are current users of

\section{Correspondence:}

\section{Dr. Sirjana Dahal}

Department of Community and Public Health Dentistry, Kathmandu Medical College and Teaching Hospital, Bhaktapur, Nepal. email:sirjanadahal11@gmail.com

\section{Citation}

Dahal S, Poudel P, Adhikari S. Nicotine Dependence and Periodontal Status among Tobacco Users in a Dental Hospital of Kathmandu Valley. J Nepal Soc Perio Oral Implantol. 2020 Jul-Dec;4(8):78-82. tobacco (3.8 million adults) ${ }^{5}$ and in a survey, 20.4\% tobacco smokers showed high nicotine dependence. ${ }^{6}$

Tobacco is a significant risk factor affecting prevalence, extent, and severity of periodontitis. ${ }^{2}$ A hospital-based study conducted in Nepal revealed that most of the tobacco users (86.4\%) had periodontitis. ${ }^{7}$ Exposure to high nicotine concentration causes alteration in gingival blood flow, gingival crevicular fluid, connective tissue turnover, and cell function of periodontium leading to increased pocket depths, loss of periodontal attachment, alveolar bone height, and higher rate of tooth loss. ${ }^{2}$ This study was conducted to assess the nicotine dependence and periodontal status among tobacco users in a dental hospital of Kathmandu valley and determine their association.

\section{METHODS}

A cross-sectional study was conducted from July to October 2020, among 164 individuals visiting the dental hospital of Kathmandu Medical College. Ethical clearance was obtained from the same institution. Individuals of age group 15-69 years using any forms of tobacco (smoking 
or smokeless) for more than six months were selected by convenience sampling method. Individuals with history of any periodontal treatment for the past six months or using any medication that affects the health of periodontium, those with any chronic systemic diseases and conditions affecting periodontal health, pregnant or lactating mothers or those under nicotine replacement therapy were excluded from the study. Informed consent was sought from the study participants prior to data collection.

Sample size was calculated using formula: $\mathrm{n}=\mathrm{Z}^{2} \mathrm{pq} / \mathrm{e}^{2}$, where $\mathrm{Z}=1.96$ at $95 \%$ confidence interval, $\mathrm{p}=$ prevalence of periodontitis among smokers $=84.5 \%,^{7} \quad \mathrm{q}=100-\mathrm{p}$, $\mathrm{e}=$ permissible error (absolute) $=6 \%$. Placing these values in the provided formula, $n=139.76$. Adding $15 \%$ non-response rate, total sample size $=160.72 \approx 164$ was considered.

The tobacco users included in the study were interviewed with standard pretested and validated questionnaire. Questions about socio-demographic profile (including age, sex) and pattern of substance use (first age of tobacco use, number of years since use, type of substance) were asked. Questions to determine the presence of nicotine dependence were assessed using the Fagerstrom Test for Nicotine Dependence (FTND) questionnaire ${ }^{8}$ and the Fagerstrom Test for Nicotine Dependence-Smokeless Tobacco (FTND-ST) questionnaire. ${ }^{9}$ Both the questionnaires contained six questions each and the scores ranged from 0 to 10 . Nicotine dependence was measured based on the scores and categorised as high dependence (7-10), moderate dependence (4-6) and low dependence $(<4)$. Periodontal status was examined by using Community Periodontal Index (CPI WHO 1997) and loss of attachment (LOA). ${ }^{10}$ Depending upon the scores obtained; periodontal status of tobacco users was further categorised to "Healthy periodontium" group, "gingivitis" group and "periodontitis" group.
Data were entered in Microsoft excel sheet and analysed in IBM SPSS Statistics for Windows, version 20 (IBM Corp., Armonk, N.Y., USA). Mean and standard deviation were calculated for quantitative data. Frequency and percentage were calculated for qualitative data. Chi-square test and Fisher's exact test were used to determine the association between variables.

\section{RESULTS}

The mean age of the study participants was $44.63 \pm 15.73$ years. Out of 164 tobacco users, 133 (81.1\%) were males and 31 (18.9\%) were females. More than half of the study participants $(85,51.8 \%)$ used both smoked and smokeless forms of tobacco followed by only smoked form (54, 32.9\%) and only smokeless form $(25,15.2 \%)$. Smokers started their first cigarette/bidi at $19.32 \pm 4.15$ years and their mean smoking duration was $24.82 \pm 15.76$ years. The first age of using smokeless tobacco by tobacco chewers was $20.36 \pm 4.96$ years and their mean duration of using smokeless tobacco was $25.65 \pm 15.93$ years. Most of the males $(79,59.4 \%)$ used both the forms of tobacco whereas majority of females (20, 64.5\%) used smoked form (Table 1).

The level of nicotine dependence among different types of tobacco users are shown in Figure 1 and 2. Most of the tobacco smokers, chewers and dual users had low level of nicotine dependence. Majority of the tobacco users surveyed had periodontal pocket of $4-5 \mathrm{~mm}(73,44.5 \%$, Figure 3$)$ and loss of attachment of 6-8 mm (79, 48.2\%, Figure 4). Increased duration of tobacco smoking and chewing was significantly associated with periodontitis $(\mathrm{P}<0.001, \mathrm{P}<0.001$ respectively). Tobacco smokers and chewers having moderate and high nicotine dependence had periodontitis significantly higher than those who had low dependence (Table 2).

Table 1: Distribution of tobacco users according to sex.

\begin{tabular}{|l|c|c|c|c|}
\hline \multicolumn{1}{|c|}{ Sex } & Smoked form & Smokeless form & Dual user & P value \\
\hline Male & $34(25.6 \%)$ & $20(15.0 \%)$ & $79(59.4 \%)$ & $<0.001$ \\
\hline Female & $20(64.5 \%)$ & $5(16.1 \%)$ & $6(19.4 \%)$ & $85(51.8 \%)$ \\
\hline Total & $54(32.9 \%)$ & $25(15.2 \%)$ & & \\
\hline Chi-square test. & & & &
\end{tabular}

Chi-square tes

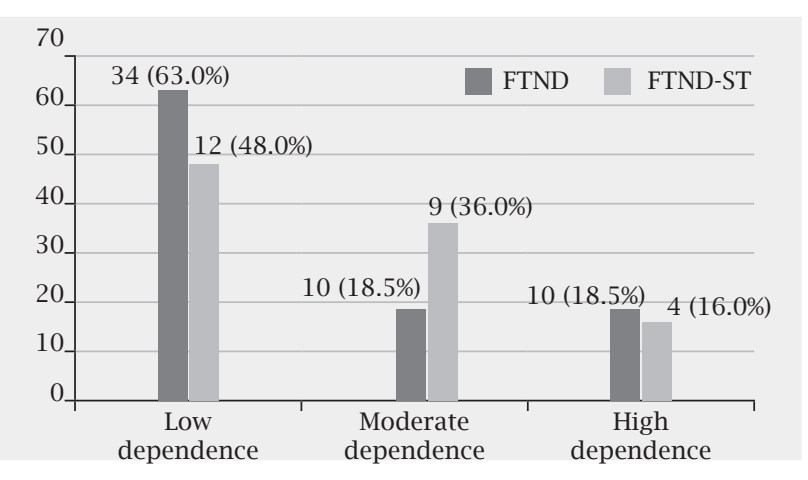

Figure 1: Level of nicotine dependence among tobacco smokers using FTND and tobacco chewers' users FTND-ST.

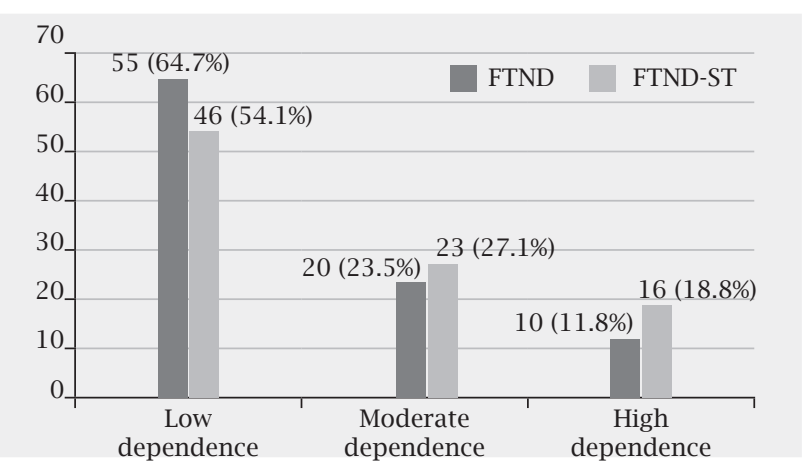

Figure 2: Level of nicotine dependence among dual users (smoking:FTND, smokeless: FTND-ST). 


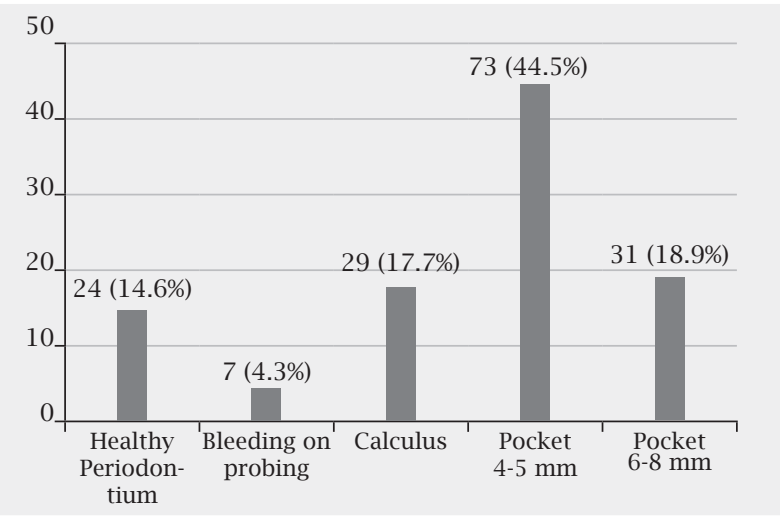

Figure 3: Distribution of study participants according to CPI scores.

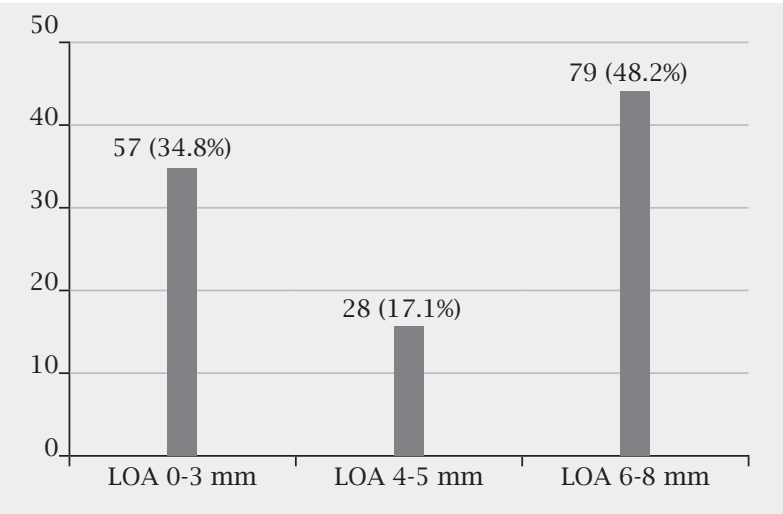

Figure 4: Distribution of study participants according to loss of attachment scores.

Table 2: Association of different variables with periodontal status.

\begin{tabular}{|c|c|c|c|c|c|}
\hline \multirow{2}{*}{ Variables } & \multirow{2}{*}{ Categories } & \multicolumn{3}{|c|}{ Periodontal status } & \multirow{2}{*}{$P$ value } \\
\hline & & Healthy periodontium & Gingivitis & Periodontitis & \\
\hline \multirow{3}{*}{$\begin{array}{l}\text { Forms of tobacco con- } \\
\text { sumed }\end{array}$} & Smoke & 18 (33.3\%) & $5(9.3 \%)$ & $31(57.4 \%)$ & \multirow{3}{*}{$<0.001 *$} \\
\hline & Smokeless & $2(8.0 \%)$ & $6(24.0 \%)$ & 17 (68.0\%) & \\
\hline & Both & $4(4.7 \%)$ & 25 (29.4\%) & $56(65.9 \%)$ & \\
\hline \multirow{3}{*}{$\begin{array}{l}\text { Smoking duration among } \\
\text { smokers only and dual } \\
\text { users }\end{array}$} & $<10$ years & $13(48.1 \%)$ & 9 (33.3\%) & $5(18.5 \%)$ & \\
\hline & 10-19 years & $4(10.0 \%)$ & $14(35.0 \%)$ & $22(55.0 \%)$ & \\
\hline & $\geq 20$ years & $5(6.9 \%)$ & $7(9.7 \%)$ & $60(83.3 \%)$ & \\
\hline \multirow{3}{*}{$\begin{array}{l}\text { Chewing duration among } \\
\text { chewers only and dual } \\
\text { users }\end{array}$} & $<10$ years & $3(12.5 \%)$ & $12(50.0 \%)$ & $9(37.5 \%)$ & \multirow{3}{*}{$<0.001 \dagger$} \\
\hline & 10-19 years & $2(7.1 \%)$ & $14(50.0 \%)$ & $12(42.9 \%)$ & \\
\hline & $\geq 20$ years & $1(1.7 \%)$ & $5(8.6 \%)$ & $52(89.7 \%)$ & \\
\hline \multirow{3}{*}{$\begin{array}{l}\text { Nicotine dependence in } \\
\text { smokers and dual users } \\
\text { due to smoking using } \\
\text { FTND }\end{array}$} & Low dependence & 19 (21.3\%) & 28 (31.5\%) & $42(47.2 \%)$ & \multirow{3}{*}{$<0.001 \dagger$} \\
\hline & Moderate dependence & $3(10.0 \%)$ & $2(6.7 \%)$ & $25(83.3 \%)$ & \\
\hline & High dependence & $0(0 \%)$ & $0(0 \%)$ & 20 (100\%) & \\
\hline \multirow{3}{*}{$\begin{array}{l}\text { Nicotine dependence in } \\
\text { chewers and dual users } \\
\text { due to smokeless tobacco } \\
\text { using FTND-ST }\end{array}$} & Low dependence & $5(8.6 \%)$ & $31(53.4 \%)$ & $22(37.9 \%)$ & \multirow{3}{*}{$<0.001 \dagger$} \\
\hline & Moderate dependence & $0(0.0 \%)$ & $0(0.0 \%)$ & 32 (100.0\%) & \\
\hline & High dependence & $1(5.0 \%)$ & $0(0.0 \%)$ & 19 (95.0\%) & \\
\hline
\end{tabular}

\section{DISCUSSION}

Tobacco use is a primary cause of many oral diseases including periodontal disease. Nicotine is one of the substances present in tobacco that causes addiction. ${ }^{11}$ This study was conducted to assess the nicotine dependence and periodontal status among tobacco users (smokers, chewers or dual users) in Kathmandu Medical College and Teaching Hospital.

More than half of the tobacco users $(85,51.8 \%)$ surveyed in this study consumed both smoked and smokeless forms of tobacco. Males $(79,59.4 \%)$ consumed tobacco in both forms more than females $(6,19.4 \%)$ and the difference was statistically significant. A narrative review of Nepal reported findings of twenty studies having higher prevalence of smoking as well as consumption of smokeless tobacco among males. Also, males were three times more likely to smoke than females. ${ }^{12}$
Nicotine is an addictive substance that induces pleasure thereby reducing stress and anxiety. ${ }^{13}$ When nicotine is inhaled through tobacco smoke, it enters the circulation rapidly through lungs and moves into the brain within few seconds. ${ }^{14}$ Smokers consume tobacco to modulate levels of arousal and to control mood. Smoking also improves concentration and performance of certain tasks. ${ }^{13}$ In the present study, majority of tobacco smokers $(34,63 \%)$ and chewers $(12,48 \%)$ showed low level of nicotine dependence when assessed using FTND and FTND-ST questionnaire. Also, more than half of the dual users had low dependence due to smoking $(55,64.7 \%)$ and consumption of smokeless tobacco (46, 54.1\%). This finding is similar to a community-based study done in Nepal, where most of tobacco smokers (49\%) had very low to low dependence. ${ }^{6}$ However, in a study done by Goyal et al. most of the tobacco chewers had high nicotine dependence than smokers. ${ }^{15}$ 
Although periodontal diseases are caused primarily by dental plaque, risk factors like tobacco consumption can modify the periodontal response to microbial aggression. ${ }^{16}$ In the current study, most of the tobacco users $(73,44.5 \%)$ had chronic periodontitis with periodontal pocket of $4-5$ $\mathrm{mm}$ and attachment loss of $6-8 \mathrm{~mm}(79,48.2 \%)$ followed by periodontal pocket of $6-8 \mathrm{~mm}(31,18.9 \%)$ and clinical attachment loss of 4-5 mm (28, 17.1\%). Very few (24, 14.6\%) tobacco users had healthy periodontium. Tobacco users in the present study were further categorised as smokers only, chewers only and dual users (using both smoke and smokeless form). On periodontal examination, majority of tobacco smokers $(31,57.4 \%)$, chewers $(17,68.0 \%)$ and dual users $(56,65.9 \%)$ had periodontitis. Some of the smokers $(18,33.3 \%)$ had healthy periodontium and very few of them $(5,9.3 \%)$ had gingivitis. Only two tobacco chewers (8\%) and four (4.7\%) dual users had healthy periodontium. Comparable results are shown by a study done in rural Nepali population by Pradhan et al., where light and heavy smokers have deeper periodontal pockets than nonsmokers. ${ }^{17}$ Similarly, in a hospital-based study conducted by Rajkarnikar and Acharya, most of the tobacco users as smokers (84.5\%), chewers (100\%) and dual users (86.4\%) had higher periodontal breakdown. ${ }^{7}$ Two studies done by Gupta et al. in Bir hospital ${ }^{18}$ and Kantipur dental college ${ }^{19}$ showed smokers having higher presence of periodontitis than nonsmokers. However, in the former study, the difference was not statistically significant. Smoking is an independent, well established and modifiable risk factor of periodontal disease having destructive effect to periodontal tissues like increase in probing depths, two to eight fold increase in periodontal attachment loss, significant bone, and tooth loss..$^{20}$ Due to alteration in gingival vasculature, it shows lower gingival bleeding and less gingivitis. ${ }^{21}$

The duration of tobacco use is also an important determinant of periodontal disease progression. ${ }^{22}$ In this study, significant association between duration of tobacco consumption in both smoking $(\mathrm{P}<0.001)$ and smokeless $(\mathrm{P}<0.001)$ form and severity of periodontal disease was seen. Most of the tobacco smokers $(60,83.3 \%)$ and chewers $(52,89.7 \%)$ who consumed tobacco for more than 20 years had presence of periodontitis. A study done among Nepalese population by Dhami et al. revealed similar results where individuals smoking for 20 years or more had higher Community Periodontal Index of Treatment Needs (CPITN) scores (periodontal pocket of $4 \mathrm{~mm}$ and above) than those who smoked for less years. ${ }^{23}$ Similarly, in a study, Calsina et al. reported that the probability of having periodontitis was 3.7 fold higher in those who had been smoking for 10 years or more. ${ }^{24}$ Likewise, Hashmin et al. also reported that chronic exposure to smoking was a strong predictor of periodontal disease prevalence. ${ }^{25}$

In the present study, all the tobacco users having high nicotine dependence $(20,100 \%)$ due to tobacco smoking and moderate $(32,100 \%)$ to high dependence (19, 95\%) due to tobacco chewing had significantly greater presence of periodontitis than those having low dependence. In accordance to this study, nicotine dependence was found to be significantly correlated with periodontal status and loss of attachment in a study done by Goyal et al. among nicotine dependent individuals attending community dental camps. ${ }^{14}$

This study has some limitations. Since the study is crosssectional in nature, the association shown cannot ascertain causality of disease. Prospective longitudinal studies would be required for better assessment of causality. The study participants were selected by convenience sampling method in a single dental setting. Therefore, the study findings are limited to a dental hospital only. Furthermore, interview method was used to assess the nicotine dependence due to which information bias (interviewer bias, recall bias, telescopic bias) could be unavoidable.

\section{CONCLUSION}

The findings in this study conclude that nicotine dependence is significantly associated with increased periodontal breakdown. In order to prevent and control tobacco induced oral diseases, health education, tobacco cessation, and motivational activities should be prioritised at national and international level.

\section{ACKNOWLEDGEMENT}

We would like to acknowledge and thank all the participants for their active participation in this study.

\section{Conflict of Interest: None.}




\section{REFERENCES}

1. Pallavi P, Amith HV, Garima B, Vani S, Bhanupriya T, Ankita S. Assessment of nicotine dependence among the tobacco users in outreach programs: A questionnaire based survey. Int J Oral Health Med Res. 2015;2(3):34-8.

2. Malhotra R, Kapoor A, Grover V, Kaushal S. Nicotine and periodontal tissues. J Indian Soc Periodontol. 2010;14(1):72-9.

3. Chahal GS, Chhina K, Chhabra V, Chahal A. Smoking and its effect on periodontium - Revisited. Indian J Dent Sci. 2017;9(1):44-51.

4. Divinakumar KJ, Patra P, Prakash J, Daniel A. Prevalence and patterns of tobacco use and nicotine dependence among males industrial workers. Ind Psychiatry J. 2017 Jan;26(1):19-23.

5. Nepal STEPS survey 2019. Tobacco Fact Sheet. 2019. Available from: http://nhrc.gov.np/wp-content/uploads/2019/11/Tobacco-FactSheet-1.pdf. Last accessed: 29th October 2020.

6. Aryal UR, Bhatta DN, Shrestha N, Gautam A. Assessment of nicotine dependence among smokers in Nepal: a community based crosssectional study. Tob Induc Dis. 2015 Dec 1;13(1):26-34.

7. Rajkarnikar J, Acharya J. Prevalence and severity of periodontal diseases among Nepalese adults-a hospital based study. J Coll Med Sci. 2014;10(1):11-6.

8. Heatherton TF, Kozlowski LT, Frecker RC, Fagerstrom KO. The Fagerström test for nicotine dependence: a revision of the Fagerstrom tolerance questionnaire. Br J Addict. 1991 Sep;86(9):1119-27.

9. Ebbert JO, Patten CA, Schroeder DR. The Fagerström test for nicotine dependence-smokeless tobacco (FTND-ST). Addict Behav. 2006 Sep 1;31(9):1716-21.

10. World Health Organization. WHO basic oral health survey (4th ed). Geneva, Switzerland: World Health Organization. 1997.

11. Mubeen K, Chandrashekhar H, Kavitha M, Nagarathna S. Effect of tobacco on oral-health an overview. J Evol Med Dent Sci. 2013 May 20;2(20):3523-35

12. Khanal GN, Khatri RB. Burden, prevention and control of tobacco consumption in Nepal: a narrative review of existing evidence. Int Health. 2020 Sep 11;0:1-12.

13. Benowitz NL. Nicotine addiction. N Engl J Med. 2010 Jun 17;362(24):2295-303.

14. Samaha AN, Yau WY, Yang P, Robinson TE. Rapid delivery of nicotine promotes behavioral sensitization and alters its neurobiological impact. Biol Psychiatry. 2005 Feb 15;57(4):351-60.

15. Goyal J, Menon I, Singh RP, Gupta R, Sharma A, Bhagia P. Prevalence of periodontal status among nicotine dependent individuals of 35-44 years attending community dental camps in Ghaziabad district, Uttar Pradesh. J Family Med Prim Care. 2019 Jul;8(7):2456-62.

16. Calsina G, Ramon JM, Echeverria JJ. Effects of smoking on periodontal tissues. J Clin Periodontol. 2002;29:771-6.

17. Pradhan S, Bhat MK. Assessment of periodontal status of rural Nepalese population using the community periodontal index. J Nepal Dent Assoc. 2009;10(2):97-104

18. Gupta S, Pradhan S, Sushil KC, Shakya S, Giri M. C-reactive protein in periodontitis and its comparison with body mass index and smoking behaviour. J Nepal Med Assoc. 2017 Apr 1;56(206):226-33.

19. Gupta S, Maharjan A, Dhami B, Amgain P, Katwal S, Adhikari B, Shukla A. Status of tobacco smoking and diabetes with periodontal disease. J Nepal Med Assoc. 2018 Sep 1;56(213):818-24.

20. Goel K, Gorkhali RS, Pradhan S, Gupta S. Impact of smoking and smoking cessation on periodontal health: a review. J Nepal Soc Periodontol Oral Implantol. 2017 Dec 4;1(2):65-71.

21. Bergstrom J, Eliasson S, Dock J. A 10-year prospective study of tobacco smoking and periodontal health. J Periodontol. 2000;71(8):1338-47.

22. Mullally BH. The influence of tobacco smoking on the onset of periodontitis in young persons. Tobo Induc Dis. 2004 Jun;2(2):1-3.

23. Dhami B, Shrestha P, Humagain M. Effect of cigarette smoking on periodontal health status in Nepalese population. J Nepal Dent Assoc. 2013;13(2):16-21.

24. Calsina G, Ramon J-M, Echeverria J-J. Effects of smoking on periodontal tissues. J Clin Periodontol. 2002 Aug; 29(8): 771-6.

25. Hashim R, Thomson WM, Pack ARC. Smoking in adolescence as a predictor of early loss of periodontal attachment. Community Dent Oral Epidem. 2001; 29(2): 130-5. 